\section{Waterfowl and rice in California's Central Valley}

\author{
Frederic A. Reid a Mickey E. Heitmeyer
}

Wetlands of California's Central Valley historically held one of the largest concentrations of wintering waterfowl in the world. In wet winters, some 2 million to 4 million acres of seasonal and semi-permanent wetlands were flooded in the Valley. It is estimated that as many as 40 million to 50 million waterfowl once funneled down the Pacific Flyway - from the arctic tundra of the Northwest Territories, the boreal forests of Alaska, the prairies of Canada, and the alkaline flats of the Great Basin - to the Central Valley. As recently as the 1970 s, some 10 million to 12 million swans, geese, and ducks wintered in or migrated through California; large numbers of other waterbirds such as shorebirds, cranes,

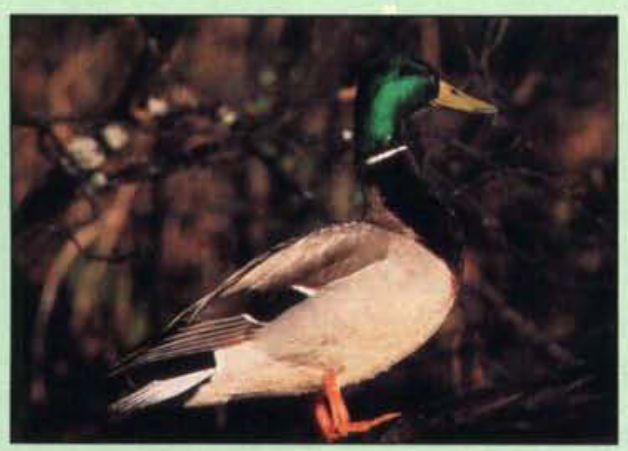

highly dependent on harvested grain fields - rice, wheat, milo, and barley - for food in migration and winter. Harvested rice fields have been an important habitat component in filling some of the nutritional and energetic needs of several waterfowl species. Those that are common in shallowly flooded rice fields include the whitefronted goose, snow goose and Ross' goose; the tundra swan; and the mallard, northern pintail, green-winged teal and American widgeon. Less common species that use harvested rice fields include the gadwall, northern shoveler and bufflehead.

Although ricefields do not directly replace the value of lost wetlands, saturated or shallowly flooded rice fields add to the complex of other small-grain wading birds, rails, grebes and gulls also came.

The conversion of historic wetlands in California has been extensive. Less than 330,000 acres of wetlands remain in the Central Valley, and most of these systems have been hydrologically altered so that intensive water management by either public or private entities is required to mimic seasonal cycles. Today the Central Valley supports only 3 million to 6 million wintering waterfowl - still one of the largest single concentrations in North America. These waterfowl represent more than $60 \%$ of all those wintering in the Pacific Flyway and approximately $20 \%$ of all those wintering in North America.

Because of these wetland limitations, many waterfowl species are critical wintering habitat of Pacific Flyway waterfowl. As conditions improve in the prairie pothole breeding region of Canada and the United States (including Manitoba, Saskatchewan, Alberta, the Dakotas, Minnesota and eastern Montana), true conjunctive use of grain production and waterbird wintering habitat will be critical to waterfowl survival and recruitment.

F.A. Reid is Regional Biological Supervisor, Ducks Unlimited, Inc., Sacramento, and M.E. Heitmeyer is Director of Institute for Wetland and Waterfowl Research, Ducks Unlimited, Inc., Memphis, Tenn. Photo courtesy of Ducks Unlimited, Inc.

\section{continued from page 60}

will depend on demonstrating a favorable agro-economic cost-to-benefit ratio, meaning the cost is reasonable and the practice is not harmful to the farming operation. Preliminary cost comparisons of the different methods of straw incorporation favor rolling, which appears to be one of the least expensive methods. The standard technique for straw incorporation requires chopping the straw into pieces, discing the stubble into soil, and ensuring there is enough moisture for microbes to grow and decompose the stubble. The large machines that chop and disc the massive quantities of straw have a high energy cost. According to a recent analysis of the fall costs of processing straw, incorporation with a disc, plow or tiller costs from $\$ 10$ to $\$ 80$ per acre (table 2 ) while rolling a field one time costs $\$ 6$ per acre at most.

However, this analysis did not include either the cost of the water for postharvest reflooding or the cost of additional spring field operations necessitated by insufficient winter straw decomposition. In addition, the cost of rolling fields may be increased by possible agronomic effects on the development and yield of the subsequent crop. Developing a better understanding of these unknowns is critical to encouraging rice growers to manage straw residue by flooding and rolling their fields.

\section{Agronomic considerations}

Little is known about how well rice straw decomposes in temperate climates under the flooded, largely anaerobic conditions typical of wet rolling, a novel technology. Somewhat more is known about straw decomposition when the temperature is suboptimal and the soil moisture varies, conditions that typify the standard nonflooded technique of straw incorporation.

The primary determinants of the rate and extent of decomposition, and therefore the subsequent nutrient availability to the rice crop, are temperature, soil water content, amount and placement of straw residue, carbon-to-nitrogen ratio in the straw, native soil fertility and oxygenation 